\title{
Produção de açúcar e álcool vs. responsabilidade social corporativa: as ações desenvolvidas pelas usinas de cana-de-açúcar frente às externalidades negativas
}

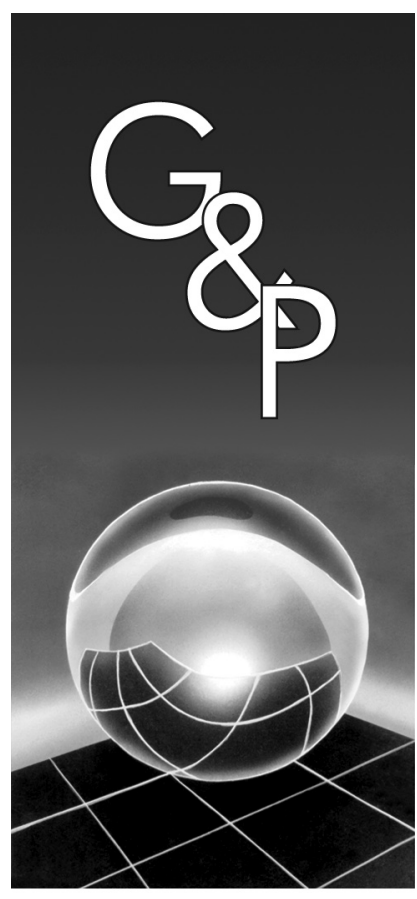

\author{
Ivelise Rasera Bragato \\ Elisabete Stradiotto Siqueira \\ Graziela Oste Graziano \\ Eduardo Eugênio Spers
}

\section{Resumo}

A responsabilidade social corporativa $(R S C)$ é analisada neste estudo no ambiente organizacional das usinas de cana-de-açúcar paulistas que integram o agronegócio brasileiro de açúcar e álcool. Trata-se de uma pesquisa qualitativa que utiliza dados quantitativos para fins descritivos. Apoiada em dados secundários e primários, aborda-se um estudo exploratório no contexto das usinas de canade-açúcar do Estado de São Paulo. O objetivo geral foi estabelecer uma análise comparativa entre as externalidades negativas e as ações sociais e verificar se estas últimas tinham um papel compensatório. Foi possível identificar a relação entre imagem e RSC no cenário organizacional das usinas, ressaltando as principais ações sociais desenvolvidas pelas empresas, as quais vêm contribuindo para a melhoria da imagem do setor sucroalcooleiro como agente participante do desenvolvimento sustentável. Constatou-se que o foco das ações sociais está concentrado nas áreas educacional e ambiental, ocupando um plano secundário as ações relacionadas à cultura, ao esporte e à saúde. Os resultados demonstraram que o número de projetos sociais não está necessariamente relacionado ao porte das empresas pesquisadas.

Palavras-chave: Responsabilidade social corporativa. Processo produtivo. Usinas de açúcar e álcool. Ações sociais. Externalidades negativas.

\section{Introdução}

A lógica econômica que predominou no século XX foi caracterizada por alguns princípios, tais como: a intensa utilização da tecnologia, a qual pode resultar em desemprego por meio da utilização de práticas de corte nos postos de trabalho; a ênfase no mercado internacional em detrimento do doméstico; e as reorganizações nas empresas com a finalidade de ampliar a produtividade e não a produção (CEVOLI, 1999).

Tal perspectiva de atuação empresarial no contexto social produziu uma série de ameaças em relação ao futuro, bem como problemas socioeconômicos que carecem de medidas urgentes. Os principais focos de degradação estão na dimensão ambiental e social.

A busca de solução tem sido procurada no plano técnico, no âmbito de alternativas tecnológicas que contribuam para a reversão do quadro de degradação e também da postura gerencial, principalmente no que diz respeito à construção de uma nova imagem do setor no campo empresarial, que em longo prazo poderia se constituir em uma racionalidade orientada em valores mais equilibrados na sua relação com a sociedade (ANDRADE et al., 2004).

Historicamente, as práticas administrativas têm sido orientadas pela razão instrumental, que segundo Serva (1997), seria um dos fatores que tem gerado condições degradantes do meio ambiente e das relações humanas. Em contraposição a tal perspectiva e apoiado na proposta de Guerreiro Ramos, o autor sugere a operacionalização do conceito de racionalidade substantiva, que teria na ética a sua regra de conduta para a vida social. Essa racionalidade, apoiada no pensamento aristotélico, transcende a relação entre razão e cálculo, permitindo que os indivíduos busquem a auto-realização e a satisfação social altruisticamente, através dos debates e do julgamento ético-valorativo.

No sentido de uma mudança de orientação das práticas administrativas, Melo Neto e Froes (2001, p.4-6) sugerem: 


\begin{abstract}
"A modificação dessa racionalidade significa a mudança da racionalidade das empresas. Assim, a saída encontrada foi a criação de uma nova lógica e racionalidade social. Ela surge não para substituir a lógica econômica globalizante, mas para atenuar seus efeitos e diminuir seus riscos sistêmicos". (MELO NETO; FROES, 2001, p.4-6).
\end{abstract}

Assim, a imagem organizacional apresenta algumas particularidades, tais como: as empresas como principais agentes; o foco na comunidade e não na sociedade; a ênfase na prática da solidariedade empresarial e não local; o desenvolvimento da comunidade a partir das ações sociais empresariais; e a empresa vista como grande investidor social, e não o Estado ou a sociedade (MELO NETO; FROES, 2001, p.7).

É a partir dessa perspectiva que se assiste ao surgimento do conceito de responsabilidade social corporativa (RSC), que representa "alcançar sucesso comercial nas maneiras que honrem valores éticos e respeito às pessoas, comunidades e ambiente natural". (BUSINESS FOR SOCIAL RESPONSIBILITY, 2006).

No caso específico do setor sucroalcooleiro, Rui (2004) comenta que a temática RSC teve início como uma ação filantrópica num primeiro momento, quando o "usineiro" exercia poderes decisórios na vida da comunidade. Com a formação de negócios familiares, por meio da administração de fazendas de cana-de-açúcar, esse modelo fez dessas empresas as principais responsáveis pelo fator social e cultural da região onde estavam localizadas, em especial nas pequenas cidades. Surgia, então, o auxílio na construção de igrejas, a participação na vida pública (prefeitos e vereadores), a construção de praças públicas e cinemas, a criação e manutenção de times de futebol, as festas juninas e natalinas nas fazendas e a gratificação espontânea de Natal.

Numa época mais recente, o poder do Estado passa a interferir na política social e filantrópica dos empresários do setor (que até então eram usineiros) e promulgam a Lei 4.860 de 1965, denominada de Plano de Assistência Social (PAS), obrigando a aplicação de $1 \%$ da produção de cana, $1 \%$ da produção e comercialização do açúcar e $2 \%$ da produção e comercialização do álcool em benefícios sociais para os colaboradores e dependentes.

Esta relação entre as expectativas da sociedade e as possibilidades de ação da organização produz uma imagem organizacional desta última que orienta sua visibilidade pública. De acordo com Machado (2003), a imagem organizacional é a visão externa que a empresa promove através de sua atuação no campo social, cultural, técnico e econômico, constituindo-se elemento contributivo de sua identidade organizacional.

Assim, este artigo aborda como o processo produtivo de açúcar e álcool desenvolve ações de RSC no contexto das usinas paulistas de cana-de-açúcar, a fim de permitir a compreensão dessas práticas nesse contexto organizacional, considerando as externalidades positivas e negativas da atividade canavieira. Além disso, aponta aspectos que poderão ser desenvolvidos e aprimorados pelas usinas em relação às ações sociais, bem como a concentração destas usinas em algumas áreas de atuação menos ampliadas.

Considera-se externalidade quando:

"as ações de alguns agentes interferem no bem-estar dos demais, sem que haja a devida incorporação dos benefícios ou custos criados por parte dos responsáveis por essas ações. No primeiro caso, a externalidade é dita positiva e no segundo é negativa". (KNIGHT; YOUNG, 2006, p.3).

Trata-se de uma pesquisa qualitativa que utiliza dados quantitativos para fins descritivos. Apoiada em dados secundários obtidos por intermédio de materiais divulgados pela União da Indústria de Cana-de-Açúcar (Unica) e primários, aborda-se um estudo exploratório no contexto das usinas de cana-de-açúcar do Estado de São Paulo.

A Unica é a representante do setor empresarial de produtores de cana-de-açúcar, açúcar e álcool no Estado de São Paulo com mais de 100 unidades industriais associadas, agrupada em dois sindicatos: o da Indústria de Fabricação de Álcool no Estado de São Paulo (Sifaesp) e o da Indústria de Açúcar no Estado de São Paulo (Siaesp). Formalizada em 1997 com a necessidade de organização do setor de açúcar e álcool no Brasil devido ao fim da interferência do governo (desregulamentação) no final dos anos 90, ela permitiu a unificação das ações institucionais numa só entidade, fortalecendo as relações com o governo e a sociedade. Esse novo período foi marcado pelo início do setor no livre mercado, culminando com a profissionalização da entidade em 2000, com a criação do cargo de presidente executivo e a introdução dos cargos de diretor técnico e de secretário geral em 2003.

\section{A responsabilidade social nas empresas}

\subsection{0 conceito em si}

A discussão de responsabilidade social é uma tentativa de restabelecer uma tradição de 2000 anos atrás, quando os negócios estavam intimamente relacionados com a comunidade. O surgimento do comércio na sociedade medieval inaugura uma concepção de mercadoria que atribui ao mercador a imagem de explorador. Contudo, é com a Revolução Industrial, cuja conexão está voltada unicamente para a produção do lucro, que a distância entre negócios e sociedade é finalmente selada como um antagonismo irredutível. Os impactos do mundo industrial na 
dimensão social e ambiental obrigaram os atores sociais a retomarem uma avaliação dos nexos entre organização e sociedade, e a partir de tal perspectiva o conceito de responsabilidade social foi sendo construído em diferentes contextos históricos (PANWAR et al., 2006).

Segundo Chrisman e Carroll (1984), o primeiro diálogo entre organizações e sociedade ocorreu no campo filantrópico, cuja lógica não está centrada na reversão dos impactos produzidos no meio social, mas em ações compensatórias, como doações para instituições de caridade. Não ocorre, por parte da empresa, uma mudança em sua concepção de mundo, mas apenas a compensação monetária para alguma causa social.

A segunda fase da discussão de RSC, segundo os autores, ocorre em meados das décadas de 60 e 70, quando uma série de pressões sociais obriga a empresa a considerar a dimensão social tal qual a econômica, ou seja, como uma ramificação de suas atividades.

Por fim, na terceira fase, encontram-se os traços contemporâneos do conceito que articula a responsabilidade das organizações às conseqüências de suas atividades econômicas, ou seja, não basta somente o engajamento social, mas primordialmente a reversão dos impactos produzidos com a atividade produtiva. Seria o que Senge (2001) denomina de modelo circular dos sistemas vivos, ou seja, produzir, reciclar e regenerar. Tal perspectiva se baseia em uma mudança de mentalidade que se orienta pelo incentivo a empreendimentos que não prejudiquem o tecido social e ambiental e que ao mesmo tempo sejam financeiramente viáveis.

A Figura 1 demonstra a evolução deste processo, evidenciando a relação entre a dimensão econômica e social.

Panwar et al. (2006) também propõem um modelo para compreensão do desenvolvimento do conceito de responsabilidade social. A primeira fase estaria articulada à concepção de Freedman, que concebe que o bom desempenho financeiro e produtivo da organização é por si só um bem público, uma vez que produz prosperidade. A segunda fase, que começou durante 1920, substitui a lucratividade como parâmetro único de contribuição social, e inclui a concepção da necessidade de um equilíbrio entre as diversas reivindicações que atuam em uma organização, como clientes, empregados, credores, comunidade e acionistas. A terceira fase critica os impactos socioambientais produzidos pelas organizações, principalmente aqueles vinculados a uma distribuição injusta de riquezas e aos danos ambientais no ar, no solo e na água, assim como a desconsideração com o bem-estar dos consumidores e problemas de segurança envolvendo toda a sociedade. Nesse sentido, propõe que as organizações tenham responsabilidades relacionadas com a qualidade de vida da sociedade e não somente com os resultados econômicos.

Concordando com esta última concepção, que é semelhante à fase 3 proposta por Chrisman e Carroll (1984), Sharma e Talwar (2005) sugerem que a busca de crescimento econômico não necessariamente produz progresso social. Para os autores, RSC é um conceito ético que envolve o bem-estar humano em sua dimensão mais ampla. Seu cerne está no abandono da visão exclusivista do lucro. As empresas precisam desenvolver novas medidas de desempenho que considerem a interconexão e a interdependência entre a informação, o social, o ambiental e o ético, como dimensões retroalimentadoras do sucesso empresarial que não deve ser antagônico a uma sociedade sadia.

Para além da perspectiva cronológica, Passador et al. (2005) desenvolvem uma classificação das diversas abordagens teóricas que o tema permite: Responsabilidade social como modismo; Os liberais, neoliberais e afins; Legitimação social; Uma questão ética; e a Responsabilidade social corporativa.

A dimensão do modismo se relaciona com o comportamento que os empresários julgam socialmente apropriado. Nesse sentido, um conjunto de fatores mundiais aliados às ações da ONU favoreceu a visibilidade da temática e contribuiu para que ela passasse a integrar o discurso de gestão. Os autores consideram que ainda é cedo para avaliar se tal inserção terá ou não consistência no futuro.

Na perspectiva dos liberais, o lucro deve ser a principal preocupação do gestor. A RSC deve ser efetivada na medida em que se torne uma demanda do mercado para neutralizar as ameaças à sua sobrevivência. Caso contrário, a caridade privada deve ser exercida por particulares.

A legitimação social seria conseqüência da necessidade de reestabelecimento de uma imagem positiva das empresas. Para que continuem atuando, as organizações precisam de credibilidade, uma vez que a RSC seria

\begin{tabular}{|l|l|l|l|l|l|l|l|}
\hline \multicolumn{9}{|c|}{ Consequiências } & Social & Econômica & Social \\
\hline \multirow{2}{*}{ Atividades } & Econômica & Social & Econômica & Social & & & \\
& Econômica & & & & & & \\
\cline { 2 - 8 } & Social & & & & & Fase 3 & \\
\hline
\end{tabular}

Figura 1. Fases de discussão de RSC. Fonte: Adaptado de Chrisman e Carroll (1984). 
apenas um outro mecanismo. Portanto, ela não teria um caráter transformador, mas consistiria em um deslocamento do capitalismo para combater as críticas, além de possibilitar uma nova forma de acumulação.

Na dimensão ética, a RSC se constituiria em um imperativo de sobrevivência, visto que esta seria uma postura exigida pela sociedade.

No âmbito da RSC, o conceito está apoiado na dimensão estratégica da organização. Nesse sentido, ela deveria estar alinhada aos objetivos estratégicos e deveria possibilitar que os pontos fortes do core business fossem alavancados por esse tipo de conduta.

A classificação organizada pelos autores sugere que o conceito pode ser interpretado por diferentes perspectivas, e portanto, não se constitui um consenso, mas faz parte de um processo ideológico que necessita ser considerado.

Meira (2006, p.14) alinha-se nesse campo e analisa as dimensões ideológicas presentes nessa temática. Segundo o autor, o conceito de RSC é derivado de uma tentativa de evitar a descontinuidade entre corporação e sociedade, no sentido de afirmar que entre elas não existe antagonismos, mas relações de complementariedade. Para desconstruir tal raciocínio, o autor se apóia na tese de Tragtenberg, que sugere que "a propriedade privada é o virtual impedimento da conexão entre negócios e sociedade". Mas, em uma sociedade desigual não é possível conciliar tal antagonismo.

Portanto, a temática em questão não se constitui de forma consensual e sua operacionalização pode estar orientada por diferentes perspectivas.

No âmbito da discussão proposta nesse texto, propõe-se que o conceito de RSC se estabeleça na relação organização-sociedade, não sendo possível prever os impactos que serão gerados em cada uma delas. Nesse sentido, considera-se que seu estudo pode contribuir na compreensão da complexidade que o tema envolve.

Quanto às categorias de análise, a RSC pode ser analisada considerando o público beneficiado ou o tipo de ação que desenvolve. Segundo Ashley (2002), autores clássicos da área de RSC como Howard Bowen consideram cinco tipos de públicos beneficiados com esta prática: funcionários, clientes, fornecedores, competidores e outros com os quais a empresa mantenha relações comerciais. Outra possibilidade de classificação seria aquela que engloba o público interno e externo, além do investimento na preservação ambiental.

Quanto ao tipo de ação, Melo Neto e Froes (1999, p.78) consideram uma empresa socialmente responsável aquela que engloba por meio de suas ações sociais os sete vetores de RSC: (i) apoio ao desenvolvimento da comunidade onde atua; (ii) preservação do meio ambiente; (iii) investimento no bem-estar dos funcionários e seus dependentes e num ambiente saudável de trabalho agra- dável; (iv) comunicações transparentes; (v) retorno aos acionistas; (vi) sinergia com os parceiros; e (vii) satisfação dos clientes e/ou consumidores. No presente estudo, avaliou-se cada uma das áreas de atuação - educação, meio ambiente, saúde, esporte e cultura - por intermédio das ações sociais, e verificou-se que todas as áreas se enquadram no escopo dos vetores de RSC. Tais vetores direcionam o processo de gestão empresarial para o fortalecimento da dimensão social da empresa.

\section{0 setor sucroalcooleiro no Brasil}

O setor sucroalcooleiro no Brasil é considerado evidente propulsor de desenvolvimento, com expressiva dimensão social e base de sustentação econômica do país. Segundo pesquisa sistemática do Centro de Estudos Avançados em Economia Aplicada (Cepea) em parceria com a Confederação Nacional da Agricultura (CNA), o produto interno bruto (PIB) do agronegócio brasileiro resultou num montante de $\mathrm{R} \$ 545,3$ bilhões em janeiro de 2007, com destaque para as indústrias de açúcar e de álcool, com taxa de crescimento mensal de 2,98\% e $1,2 \%$, respectivamente (BARROS; SILVA, 2007).

A atividade canavieira gera $14 \%$ dos empregos totais do país, e apenas ela reúne $6 \%$ dos empregos agroindustriais brasileiros, além de responder por $35 \%$ do PIB e do emprego rural do Estado de São Paulo. No Brasil, emprega cerca de um milhão de pessoas de forma direta, e aproximadamente quatro milhões indiretamente. Somente no Estado de São Paulo, participa com 400 mil empregos diretos, dos quais $95 \%$ dos trabalhadores paulistas possuem carteira assinada. Computando também os empregos indiretos, perfaz 1,2 milhão de empregos apenas no Estado de São Paulo (UNIÃO DA INDÚSTRIA DE CANA-DE-AÇÚCAR, 2004).

Outro efeito positivo da atividade sucroalcooleira, além dos resultados sociais, remete à diminuição dos fluxos migratórios para os municípios e o inchaço populacional urbano, com seus aspectos desfavoráveis por causa da ocupação intensiva da força de trabalho. Um dos aspectos desfavoráveis da "dinâmica do mercado de trabalho desse período é a demanda sujeita às especificidades do ciclo produtivo da cana, que gera por isso a sazonalidade característica" (GUEDES et al., 2002, p.312).

No contexto organizacional, várias melhorias de ordem agrícola, tecnológica, produtiva, administrativa e comercial, bem como o reaproveitamento dos subprodutos derivados da cana, demonstram os avanços do setor sucroalcooleiro nos últimos anos. Alguns aprimoramentos podem ser destacados: tratos culturais, plantio, irrigação e colheita da cana com a utilização de variedades desenvolvidas em experimentos para a adequação em diferentes locais de plantio; emprego de diferentes recursos no setor de automação industrial (por exemplo, moenda, 
tratamento do caldo, caldeiras, dornas de fermentação); manutenções preventivas, preditivas, detectivas e corretivas na indústria; novas técnicas de gerenciamento, tais como: reutilização dos subprodutos da cana-de-açúcar (melaço, óleo fúsel, leveduras) e co-geração de energia por meio do bagaço da cana, entre outros (SHIKIDA et al., 2002).

Em estudo realizado por Romanach e Caron (1999) em uma agropecuária do setor sucroalcooleiro do interior do Estado de São Paulo, durante a safra 98/99, concluiu-se que a utilização de $85 \%$ de colheita mecânica resultaria na diminuição de aproximadamente $44,6 \%$ do número de empregados envolvidos na colheita da cana-de-açúcar dessa empresa. Isto significa dispensar 18,3\% do total de funcionários nessa atividade ao longo da safra.

Dessa forma, a Unica assumiu um compromisso com o desenvolvimento sustentável e explicita seus propósitos transformando-os em objetivos: a promoção do açúcar e do álcool combustível por suas qualidades no que se refere à melhoria da saúde pública e do meio ambiente; o desenvolvimento de políticas que proporcionem competitividade à biomassa por ser energia limpa e renovável; a caracterização da energia da biomassa como alternativa concreta às fontes fósseis, tendo em vista suas propriedades ambientais, sociais e econômicas, tais como: redução da poluição local, melhorando o ar nos grandes centros urbanos, e da poluição global, contribuindo para a redução das substâncias que provocam o efeito estufa; a geração de emprego e de renda de forma descentralizada, contribuindo para a redução das desigualdades sociais; e a contribuição para a redução da dependência do petróleo e do consumo de combustíveis fósseis (UNIÃO DA INDÚSTRIA DE CANA-DE-AÇÚCAR, 2004).

Como qualquer outro processo produtivo, algumas externalidades negativas de ordem social, econômica e ambiental podem ser destacadas na atividade canavieira. Caron (1999, p.2) comenta que:

"tal cultura agrícola apresenta problemas de exclusão social, principalmente devido à mecanização da colheita da cana. Além do impasse social e ambiental, pois para não queimar a palha da cana a colheita deve ser mecanizada e, com isso, milhares de trabalhadores braçais são dispensados." (CARON, 1999, p. 2)

No tocante à qualidade do ar nas regiões canavieiras, estudos demonstraram que durante a queimada de canade-açúcar ocorre a liberação de gases como monóxido e dióxido de carbono e ozônio, que são poluentes e contribuem para a poluição atmosférica. Outro ponto é a ocorrência de danos à saúde humana com o aumento dos casos de doenças respiratórias em regiões canavieiras (ROMANACH; CARON, 1999).

Guedes et al. (2002) citam algumas práticas desfavoráveis da atividade canavieira, tais como: a intensificação do uso e ocupação da terra; o potencial de degradação do solo e dos rios; a poluição do ar; o uso da água pelas usinas sem retorno aos corpos d'água; entre outras.

Em 2000, um estudo da Empresa Brasileira de Pesquisa Agropecuária (Embrapa) avaliou os impactos da cultura canavieira nos meios físicos (ar, solo e água) e na fauna (nas questões relacionadas a alimento, abrigo e reprodução), considerando a cana já queimada. A análise foi elaborada com base na seguinte escala de valores: 1 - para nenhum impacto; 2 - baixo impacto; 3 - médio impacto; 4 - alto impacto; e 5 - altíssimo impacto. O Quadro 1 demonstra esses resultados.

No que diz respeito à mão-de-obra, Paixão (2000) comenta alguns aspectos das relações de trabalho na agroindústria sucroalcooleira, tais como: a informalidade das relações de trabalho nos mercados fora do setor sucroalcooleiro; os postos de trabalho sazonais; a oscilação do nível de salário dos bóias-frias durante a safra, que é computado por produção, e na entressafra é utilizado o piso salarial; a redução dos salários reais dos trabalhadores rurais como resultado do enfraquecimento da ação dos sindicatos; a exploração da força de trabalho e as condições de trabalho severas neste tipo de atividade, entre outros. O setor também vem diminuindo a geração de empregos por causa da reestruturação dos processos produtivos, como ocorre em qualquer outro setor da economia.

Nessa perspectiva, considerando aspectos positivos e negativos dessa cultura, o posicionamento estratégico

Quadro 1. Impactos da cultura canavieira no meio ambiente. Fonte: Empresa Brasileira de Pesquisa Agropecuária (2000).

\begin{tabular}{|c|c|c|c|}
\hline Meio físico & & & Avaliação \\
\hline \multirow[t]{4}{*}{$\mathrm{Ar}$} & Odores & & 2 \\
\hline & Fumaça & & 2 \\
\hline & Poeira & & 3 \\
\hline & Alergênicos & & 3 \\
\hline \multirow[t]{7}{*}{ Solo } & Conservação & & 5 \\
\hline & Recobrimento & & 5 \\
\hline & Adensamento & & 4 \\
\hline & Perda & & 3 \\
\hline & Sais & & 2 \\
\hline & Biológicos & & 1 \\
\hline & Agrotóxicos & & 1 \\
\hline \multirow[t]{3}{*}{ Água } & Sais & & 1 \\
\hline & Biológicos & & 1 \\
\hline & Agrotóxicos & & 1 \\
\hline Fauna & Alimento & Abrigo & Reprodução \\
\hline Mamíferos & & 2 & 2 \\
\hline Aves & & 2 & 2 \\
\hline Répteis & & 3 & 3 \\
\hline Anfíbios & & 1 & 1 \\
\hline Invertebrados & & 2 & 2 \\
\hline
\end{tabular}


do Brasil frente ao restante do mundo é importante por este caracterizar-se como o maior produtor mundial de açúcar e álcool e também por possuir uma das maiores matrizes energéticas "limpas" e renováveis do planeta. Porém, no aspecto da sustentabilidade, a imagem positiva do setor sucroalcooleiro deve ser construída continuamente. Tetti (2002, p.203) comenta que:

"[...] existe a necessidade de um esforço real do empresariado, inclusive com o Governo e a Sociedade Civil, em prol da sustentabilidade e no cuidado em assegurar (...) a melhoria ambiental e de contribuição ao desenvolvimento de modo geral." (TETTI, 2002, p. 203)

\section{Metodologia do estudo}

Trata-se de uma pesquisa qualitativa que utiliza dados quantitativos para fins descritivos. Malhotra (2001, p.155) a define como uma "metodologia de pesquisa não estruturada, exploratória, baseada em pequenas amostras e que proporciona insights e compreensão do contexto do problema". Apoiada em dados secundários e primários, a pesquisa aborda um estudo exploratório no contexto das usinas de cana-de-açúcar do Estado de São Paulo. Em pesquisas descritivas, segundo Haguette (1995), levantam-se as informações sobre situações específicas e relacionadas, com o intuito de oferecer a visualização da totalidade a partir de suas distinções.

Num primeiro momento, os dados qualitativos e quantitativos foram obtidos em fontes secundárias, particularmente, no relatório intitulado: "Açúcar e álcool: responsabilidade social numa história de desenvolvimento sustentável", elaborado pela Unica, representante do setor empresarial produtor de cana-de-açúcar, açúcar e álcool no Estado de São Paulo com 97 usinas associadas. Formalizada em 1997, a entidade permitiu a unificação das ações institucionais numa só organização, fortalecendo as relações com o Governo e a sociedade.

Essa publicação representa uma mostra do trabalho desenvolvido pela Unica a partir de 2002, quando ela criou um núcleo de RSC para articular e divulgar as centenas de ações sociais existentes nas áreas de educação, meio ambiente, saúde, esporte e cultura promovidas pelas usinas. A opção pelo uso desse relatório justifica-se pelo fato de se tratar de um documento oficial e público, e dessa forma, pode ser considerado como uma representação da imagem que o setor deseja que a sociedade construa sobre as usinas de cana-de-açúcar.

As informações sobre as ações sociais contidas nesse documento foram classificadas considerando as diferentes áreas de atuação dessas usinas de acordo com os princípios dos sete vetores de RSC considerados por Melo Neto e Froes (1999), quais sejam: (i) ao desenvolvimento da comunidade onde atua; (ii) preservação do meio ambiente; (iii) investimento no bem-estar dos funcionários e seus dependentes e num ambiente saudável de trabalho agradável; (iv) comunicações transparentes; (v) retorno aos acionistas; (vi) sinergia com os parceiros; e (vii) satisfação dos clientes e/ou consumidores. Após esse processo de classificação, os vetores foram agrupados em cinco áreas de atuação: saúde, educação, meio ambiente, esporte e cultura, que deram origem ao Quadro 2. A base de dados para essa análise somou 359 ações sociais desenvolvidas pelas usinas, sendo 143 na área educacional, 29 na área cultural, 90 na área ambiental, 33 na área esportiva e 64 na área da saúde.

Posteriormente, construiu-se uma listagem que mostra o número total de ações sociais de cada uma das unidades produtoras do Estado do São Paulo congregadas à Unica. Esses dados foram compilados na Figura 2 a fim de facilitar a visualização da distribuição dos projetos sociais entre as usinas. $\mathrm{O}$ uso de algarismos arábicos para identificar as usinas é justificado pelo fato de que algumas delas não autorizaram a publicação dos dados apresentados no referido gráfico. A análise desses dados, assim organizados, permitiu compreender a ocorrência de concentração das ações sociais em usinas isoladamente.

Para a definição do porte das usinas, que orientou a análise da distribuição das ações sociais relacionadas a essa dimensão, foi realizada uma entrevista com um profissional da Unica, que além de oferecer tal informação, também contribuiu para o esclarecimento do âmbito das ações sociais desenvolvidas pelas usinas associadas à entidade. Obedeceu-se aos critérios utilizados

Quadro 2. Resumo das áreas de atuação focadas pelas usinas associadas à Unica. Fonte: União da Indústria de Cana-de-Açúcar (2004). Elaborado pelos autores.

\begin{tabular}{llcccc}
\hline \multicolumn{1}{c}{ Vetores de RSC } & Áreas de atuação & Número de projetos & $\begin{array}{c}\text { Freqüiência de } \\
\text { projetos (\%) }\end{array}$ & $\begin{array}{c}\text { Número de pessoas } \\
\text { beneficiadas }\end{array}$ & $\begin{array}{c}\text { Beneficiados (\%) } \\
1,2,3,4,5,7\end{array}$ \\
$1,3,4,5,7$ & Educação & 143 & 40 & 35060 & 45,1 \\
$1,2,3,4,5,6,7$ & Cultura & 29 & 8 & 2075 & 2,7 \\
$1,3,4,7$ & Meio ambiente & 90 & 25 & 4058 & 5,2 \\
$1,3,4,5,7$ & Esporte & 33 & 9 & 7740 & 10,0 \\
Total & Saúde & 64 & 18 & 28785 & 37,0 \\
\hline
\end{tabular}


pela Unica, que toma como referência o volume de cana moído durante a safra. Foram utilizados os seguintes intervalos da quantidade de matéria-prima processada:

a) usina de pequeno porte: abaixo de 2 milhões de toneladas de cana;

b) usina de médio porte: entre 2 e 3,5 milhões de toneladas de cana; $\mathrm{e}$

c) usina de grande porte: acima de 3,5 milhões de toneladas de cana.

Concluída a sistematização dos dados secundários, buscaram-se dados primários por meio de coleta de informações realizada através de entrevistas via telefone com 40 assistentes sociais das usinas agregadas à Unica. O critério de escolha dessa amostragem foi o de acessibilidade. Para a realização das entrevistas, foram aplicadas as seguintes questões:

a) a usina onde trabalha publica balanço social?

b) como resultado dessa publicação, a usina possui alguma certificação na área socioambiental?

c) o foco das ações sociais da usina onde trabalha está no público interno ou externo? Qual o percentual dessa participação?

Considerando que o número total das usinas associadas à Unica é de 97 no Estado de São Paulo, e que destas usinas 55 realizam algum tipo de ação social, a amostra dessa pesquisa englobou $72,7 \%$ do total daquelas que desenvolvem tal prática.

\section{Resultados e discussão dos dados}

\subsection{A relação das ações sociais versus as áreas de atuação}

A análise das propostas dos projetos acrescidos de dados oferecidos pelas assistentes sociais entrevistadas permitiu relacionar os eixos da responsabilidade social às áreas de atuação, conforme mostrado no Quadro 2.

Considerando o Quadro 2, que mostra o desenvolvimento de 359 projetos de ação social pelas usinas de açúcar e álcool do Estado de São Paulo associadas à Unica, observa-se que essas iniciativas concentram-se principalmente na área educacional $(40 \%)$ e ambiental (25\%). No caso específico da educação, as ações sociais procuram responder aos entraves da exclusão social, da baixa qualificação e do analfabetismo por meio de projetos que proporcionam o desenvolvimento da comunidade onde atuam, investimento no bem-estar dos funcionários e seus dependentes, ações de melhoria da relação do empregado com a empresa e da qualidade do emprego dos funcionários. Essa área compreende o maior número de pessoas beneficiadas com as iniciativas, com atividades subdivididas em profissionalizantes, educação formal e informal, bolsas de estudo e kit escola.
O objetivo é direcionar ações sociais que privilegiem a aprendizagem, a inclusão, a integração e a alfabetização às pessoas beneficiadas.

Quanto às iniciativas direcionadas à preservação do meio ambiente, ressaltam-se aquelas relacionadas ao ar (poeira e alergênicos) e ao solo (conservação, recobrimento, adensamento e perda), que segundo estudo da Embrapa (2000), são questões que precisam ser trabalhadas e solucionadas pelas unidades produtoras. Projetos como "Projeto saneamento ambiental na região de Catanduva" da Usina São Domingos e "Projeto 3R (redução, reuso e reciclo)" da Usina Santa Cândida exemplificam algumas ações sociais para reduzir as externalidades negativas como a intensificação do uso e ocupação da terra, o potencial de degradação do solo e dos rios, e o uso da água pelas usinas sem retorno aos corpos d'água.

As atividades desenvolvidas na área da saúde focam campanhas de vacinação; prevenção de doenças transmissíveis e hipertensão; combate à dependência química; programas para gestantes; reeducação alimentar; e assistência odontológica, visando garantir a saúde dos colaboradores e da comunidade e proporcionar melhor qualidade de vida (UNIÃO DA INDÚSTRIA DE CANADE-AÇÚCAR, 2004). Ou seja, decisões empresariais que objetivam melhorias nas condições de vida das comunidades e na relação empresa-comunidade, assim como assistência social externa no sentido de contribuir para a redução dos impactos à saúde humana, estes provocados pelo meio físico como, por exemplo, a poluição do ar (poeira do ar e alergênicos) em regiões canavieiras.

No campo social, a geração de empregos pelo setor vem se traduzindo num processo de redução dos postos de trabalho por causa da reestruturação dos processos produtivos, assim como em qualquer outro setor da economia. Nesse sentido, alguns problemas relacionados à exclusão social como a mecanização da colheita e, conseqüentemente, a dispensa de trabalhadores braçais vêm sendo compensados por ações sociais. Questões como a exploração da força de trabalho na atividade canavieira têm se apresentado menos problemáticas, com ações sociais direcionadas à qualidade de vida. Como exemplo, pode-se citar o "Projeto Alongue-se" da Usina da Pedra. Na organização do trabalho, usinas mais modernas têm objetivado a elaboração de programas de envolvimento de seus empregados por meio do trabalho de psicólogos, assistentes sociais, programas assistenciais e políticas de treinamento, visando à elevação da produtividade e à redução do absenteísmo. A relação entre as ações sociais e as externalidades negativas está demonstrada no Quadro 3.

A análise elaborada com base nos sete vetores de Melo Neto e Froes (1999) permite concluir que existe a predominância das áreas de educação e meio ambiente das ações sociais das usinas de açúcar e álcool, seguidas 
pela área de saúde, e num terceiro escopo, por esporte e cultura. Por outro lado, analisando a participação dos vetores da RSC nas atividades desenvolvidas pelas usinas de açúcar e álcool, nota-se que "apoio ao desenvolvimento da comunidade onde atua", "investimento no bem-estar dos funcionários e seus dependentes e num ambiente saudável de trabalho agradável”, "comunicações transparentes" e "satisfação dos clientes e/ou consumidores" são os vetores que podem ser observados em todas as iniciativas socialmente responsáveis das empresas analisadas.

\subsection{A distribuição das ações sociais}

Analisando o número de projetos de ação social realizados pelas usinas é possível afirmar que ocorre uma concentração dessas iniciativas, conforme mostrado na Figura 2.

Observou-se um movimento de ondas caracterizado por uma oscilação expressiva em relação ao número de projetos em cada usina. A análise dos dados apontou 359 projetos existentes entre as 55 associadas paulistas que desenvolvem algum tipo de ação social, das quais

Quadro 3. Externalidades negativas vs. ações sociais. Fonte: União da Indústria de Cana-de-Açúcar (2004). Elaborado pelos autores.

\begin{tabular}{ll}
\hline $\begin{array}{c}\text { Externalidades } \\
\text { negativas }\end{array}$ & \multicolumn{1}{c}{ Exemplos de ações sociais } \\
\hline Baixa & - alfabetização para adultos; \\
qualificação dos & - projeto de qualificação; \\
funcionários & - educação para cidadania; \\
& - projeto escrever é vida; e \\
& - telessalas. \\
\hline Degradação do & - projeto preservação dos rios e nascentes; \\
solo e dos rios & - projeto adequação das áreas; \\
& - projeto reflorestamento; e \\
\hline Problemas de & - projeto preservação ambiental. \\
saúde & comunidade; \\
& - projeto ginástica laboral. \\
\hline
\end{tabular}

9 são responsáveis por $38 \%$ dos projetos ,e são as que determinam os picos na Figura 2. Neste caso, cada uma dessas usinas concentra entre 3 e $6 \%$ dos projetos desenvolvidos do total de 359 projetos. O restante dos projetos está distribuído em porcentagens que variam de 0,5 a $2,8 \%$ do total das ações sociais. A Figura 3 apresenta uma análise da distribuição dos projetos por porte da usina.

A Figura 4 demonstra que as usinas de médio porte são responsáveis por $38 \%$ das ações sociais, seguidas pelas de pequeno porte com $35 \%$ e as de grande porte com $27 \%$. Além disso, observa-se que as ações sociais concentram-se na região de Ribeirão Preto, onde se encontra a maior representatividade de usinas do Estado de São Paulo. Ou seja, das 55 usinas que desenvolvem ações sociais no território paulista, 21 alocam-se nessa região $(38,2 \%)$, e desse número, 8 são consideradas como de grande porte. Em seguida, verifica-se que a região de Piracicaba possui $20 \%$ das usinas que desenvolvem ações sociais no Estado de São Paulo. Desse percentual, que representa um número de 11 unidades produtoras, somente uma empresa é classificada como de grande porte, sendo as demais de pequeno (8 usinas) e médio porte (2 usinas).

A análise dos dados permite identificar uma relação independente entre número de ações sociais desenvolvidas e porte da empresa. Daquelas classificadas como de grande porte, que somam 11 usinas e 97 projetos sociais, verifica-se que apenas 3 possuem um índice de concentração entre 3 e $6 \%$ frente às ações sociais. As demais empresas apresentam menor representatividade no conjunto de projetos sociais que as 55 unidades produtoras paulistas desenvolvem em RSC. Por outro lado, empresas de médio porte, que são em número de 19 , possuem 137 projetos sociais. Aquelas classificadas como de pequeno porte, que somam 25 usinas, desenvolvem 125 projetos sociais. Das 9 usinas que determinam os picos no Figura 3, somente 3 delas são de grande porte.

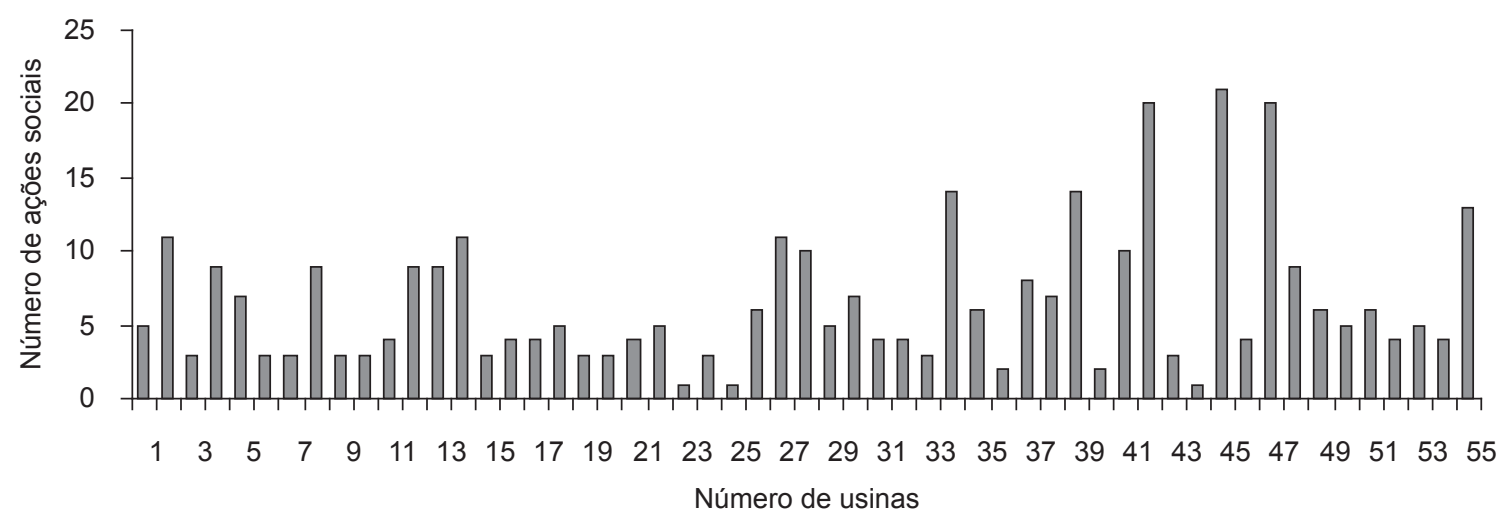

Figura 2. Distribuição das ações sociais dividida por usinas. Fonte: União da Indústria de Cana-de-Açúcar (2004). Elaborado pelos autores. 


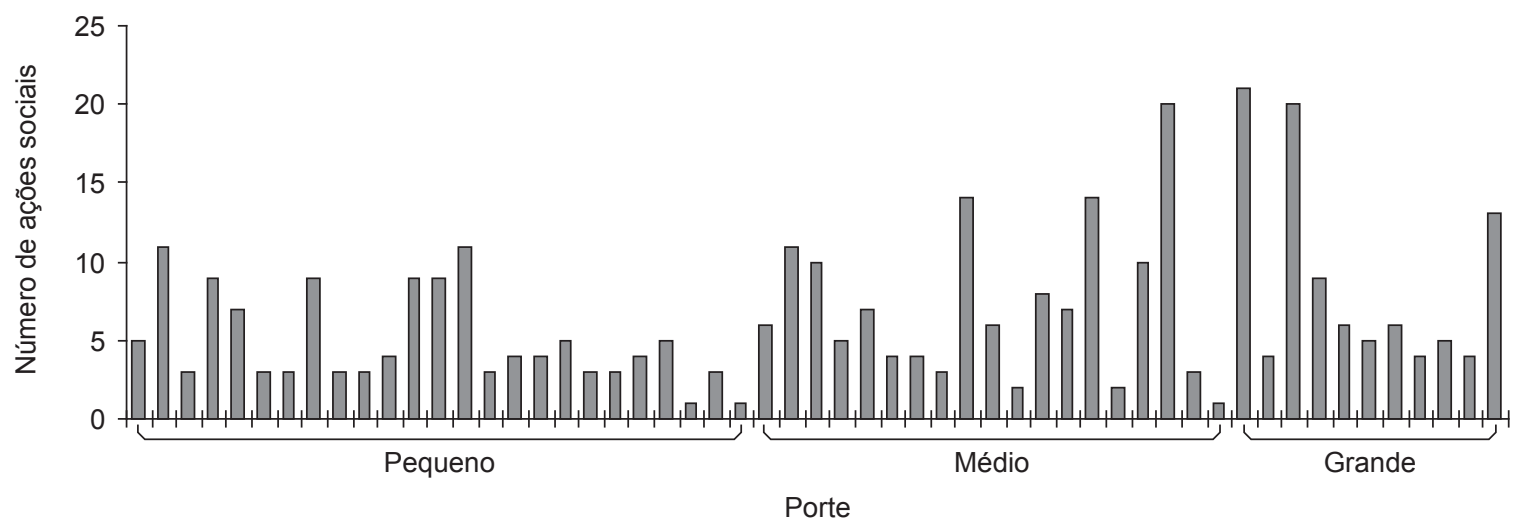

Figura 3. Distribuição das ações sociais dividida pelo porte das usinas. Fontes: União da Indústria de Cana-de-Açúcar (2004); Pesquisa de campo. Elaborado pelos autores.

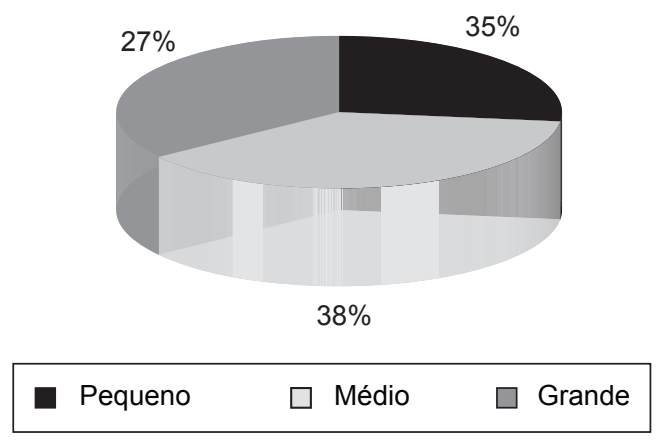

Figura 4. Relação entre porte e ações sociais desenvolvidas pelas usinas. Fonte: União da Indústria de Cana-de-Açúcar (2004). Elaborado pelos autores.

Assim, pode-se observar ocorrência de concentração das ações sociais em algumas usinas isoladamente. $\mathrm{O}$ porte da empresa não influencia o número de projetos sociais, pois necessariamente uma usina desenvolve ações sociais em maior número que as demais. Essa relação entre porte e ação social pode depender da estratégia da empresa, do foco de atuação na área social, e principalmente, da sensibilidade organizacional frente à questão da RSC.

\subsection{0 público beneficiado}

Pelos dados obtidos com as entrevistas dirigidas às assistentes sociais das usinas associadas à Unica, foi possível identificar que $32,5 \%$ das ações sociais desenvolvidas pelas usinas beneficiam tanto o público interno quanto o externo, com participação de $50 \%$ para cada público. Os funcionários das unidades produtoras são partes integrantes, atuando como beneficiados ou voluntários dessas iniciativas. O percentual de usinas que foca mais da metade de suas ações sociais no público interno é de $21,6 \%$, enquanto que $16,2 \%$ das usinas desenvolvem exclusivamente atividades direcionadas ao público interno. Vale ressaltar, que por outro lado aquelas empresas que somente focam o público externo representam um percentual bastante pequeno da amostra pesquisada $(5,4 \%)$.

Esses dados indicam que as ações sociais têm cunho compensatório no que diz respeito ao público interno, portanto, têm como foco as externalidades provocadas nas relações de trabalho, e não necessariamente uma preocupação direta com aquelas que envolvem a comunidade. Tal fator pode indicar duas possibilidades: ou consideram que o público interno é responsável significativo pela divulgação da imagem, ou não estão preocupados com o impacto das externalidades na comunidade em que se localizam. O Quadro 4 ilustra essa análise.

\subsection{As certificações}

No tocante à certificação e à realização do balanço social, os dados demonstram que $59,5 \%$ das usinas apresentam certificação na área social, principalmente o selo ABRINQ e o iBase, representando uma abertura para mercados internacionais de açúcar e álcool e um diferencial competitivo. Porém, um percentual significativo de 37,8\% ainda não possui certificação. No caso do selo iBase, a unidade produtora que realiza balanço social anualmente possui por conseqüência essa certificação, que nesse estudo foi observada em $46 \%$ das usinas analisadas. Considerando o selo ABRINQ, nota-se que $40 \%$ das usinas pesquisadas possuem esse tipo de certificação.

Nessa perspectiva, a RSC tem sua importância no fator "fortificação da imagem socialmente responsável junto a beneficiários diretos, indiretos, empresas financiadoras, comunidade, clientes, governo e imprensa" (UNIÃO DA INDÚSTRIA DE CANA-DE-AÇÚCAR, 2004, p. 25). A imagem institucional das usinas de açúcar e álcool vem sofrendo mudanças importantes, pois qualquer degeneração na imagem da empresa pode resultar em risco para a identidade organizacional. A cultura canavieira, segundo Rossetto (2004, p. 80), “carregou sozinha, por muitos anos, o ônus de ser 
Quadro 4. Público beneficiado. Fonte: Pesquisa de campo.

\begin{tabular}{lr}
\hline \multicolumn{1}{c}{ Público beneficiado } & \multicolumn{1}{c}{$\%$} \\
\hline 50\% público interno e 50\% público externo & 32,5 \\
100\% público interno & 16,2 \\
100\% público externo & 5,4 \\
Mais de 50\% público interno & 21,6 \\
Mais de 50\% público externo & 5,4 \\
Menos de 50\% público interno & 5,4 \\
70\% público interno e 30\% público externo & 5,4 \\
30\% público interno e 70\% público externo & 2,7 \\
Não responderam & 8,1 \\
\hline
\end{tabular}

uma atividade agrícola extremamente degradadora do solo, poluidora do ar e da água, causadora de grande impacto ambiental". Mas, o cenário vem se modificando nas últimas décadas. Os avanços tecnológicos e a receptividade do setor às questões relacionadas ao desenvolvimento sustentável transformaram a atividade sucroalcooleira.

\section{Considerações finais}

Este estudo abordou a temática RSC no contexto do agronegócio brasileiro, analisando as ações sociais desenvolvidas pelas usinas paulistas de açúcar e álcool a partir dos seguintes aspectos: o conceito de RSC e o ambiente organizacional, as características e as ações sociais desenvolvidas pelo setor sucroalcooleiro no Brasil.

Ao analisar a relação entre as externalidades negativas provocadas pelo setor e as ações sociais desenvolvidas, identificaram-se algumas iniciativas. Contudo, essas não atendem à reversão do quadro de degradação provocado pela atividade canavieira, podendo ser consideradas como compensatórias. Os dados divulgados pela Unica sobre as ações sociais demonstram a preocupação das usinas em projetar uma imagem positiva da atividade canavieira para a sociedade, a transparência em suas ações empresariais, bem como servir de exemplo para outros setores da economia.

O setor vive um período de transição entre a primeira e a segunda fase da discussão de RSC com ações compensatórias e não a reversão dos impactos produzidos no meio onde atuam. Suas ações sociais confundem-se com o assistencialismo, não sendo propriamente iniciativas de RSC. Assim, sugere-se que essas empresas trabalhem em função do crescimento dessas práticas no contexto atual.

Cabe lembrar, que as conquistas obtidas pelo setor sucroalcooleiro nos últimos anos no cenário internacional, como maior produtor mundial de açúcar e álcool, demandam novas posturas das usinas que integram a atividade canavieira. Ou seja, produtos de alta qualidade, livres de agrotóxicos e obtidos sob condições consideradas socialmente aceitáveis pela opinião pública internacional.

Os resultados da pesquisa mostram ocorrência de concentração das ações sociais em algumas usinas isoladamente. Os números de projetos sociais demonstram que o porte da empresa não significa que necessariamente uma usina desenvolve ações sociais em número maior que as demais. Essa relação entre porte e ação social pode depender da estratégia da empresa, do foco de atuação na área social, e principalmente da sensibilidade organizacional frente à questão da RSC.

Por fim, este artigo não visa restringir o debate em torno desta temática, mas sim contribuir para a reflexão ampliada sobre um processo complexo e abrangente, que é a RSC. Acredita-se que outros estudos possam ser desenvolvidos, na tentativa de responder outros questionamentos e complementar a análise acerca dessa prática. 


\title{
Sugar and ethanol production vs. corporative social responsibility: the actions taken by the sugar cane mills confronted with negative externalizations
}

\begin{abstract}
Corporative Social Responsibility (CSR) is analyzed in this study in the organizational environment of sugar cane mills in the state of São Paulo and which form the Brazilian agribusiness of sugar and ethanol. Following a qualitative research, the quantitative data was used to define objectives using the primary and secondary data approach; an exploratory study in the context of the sugar-ethanol mills. The goal was to establish a comparative analysis between the negative external aspects and the social actions to investigate whether the latter had a significant role. It was possible to identify the relation between image and CSR in the organizational scenario of sugar-ethanol mills highlighting the main social actions developed by the enterprises which have contributed to improving the image of the sugar-ethanol sector as an active agent in the sustainable development. It was verified that the focus of social actions are concentrated in areas related to environment and education. Those related to culture, sport, and health seemed to be not as important. The results show that the number of social actions is not, necessarily, related to the size of the companies researched.
\end{abstract}

Keywords: Corporative social responsibility. Production process. Sugar cane mills. Social actions. Negative externalization.

\section{Referências bibliográficas}

ANDRADE, R.O.B.; TACHIZAWA, T.; CARVALHO, A.B. Gestão ambiental: enfoque estratégico aplicado ao desenvolvimento sustentável. 2.ed. São Paulo: Makron Books, 2002. 232p.

ASHLEY, P.A. (Coord.). Ética e responsabilidade social nos negócios. São Paulo: Saraiva, 2002. 205p.

BARROS, G. S. C.; SILVA, S. F. PIB da agricultura cresce $0,24 \%$ em janeiro. Disponível em: <http://cepea.esalq.usp.br/pib/>. Acesso em: 18 maio 2007.

BUSINESS FOR SOCIAL RESPONSIBILITY. Corporate social responsibility. Disponível em: <http://www.bsr.org/ AdvisoryServices/CSR.cfm>. Acesso em: 22 fevereiro 2006.

CARON, D. Cana, açúcar, álcool (automóveis) e empregos. Boletim Qualidade de Vida, Piracicaba, a.1, n.4, p.1-4, set.1999.

CEVOLI, M. Bell: o advento pós-Industrial. In: DE MASI, Domenico (Org.). A Sociedade Pós Industrial. São Paulo: Senac, 2000. 443p. Tradução Anna Maria Capovilla.

CHRISMAN, J.J.; CARROLL, A.B. Corporate responsibility reconciling economic and social goals. Sloan Management Review, v.25, n.2, p.59-65,.1984

EMPRESA BRASILEIRA DE PESQUISA AGROPECUÁRIA. Monitoramento por satélite. 2003. Disponível em: < http:// www.cana.cnpm.embrapa.br/agroeco.html>. Acesso em: 22 março 2006.

GUEDES, S.N.R.; GALLO, Z.; MARTINS, L.A.T.P. Passado, presente e futuro da agroindústria canavieira do Brasil: uma reflexão a partir da perspectiva do desenvolvimento sustentável. In: MORAES, M. A. F. D. de, SHIKIDA, P. F. A. (Coords.). AgroindústriacanavieiranoBrasil: evolução, desenvolvimento e desafios. São Paulo: Atlas, 2002. p.312-319.

HAGUETTE, T.M.F. Metodologias qualitativas na sociologia. Petrópolis: Vozes, 1995. 224p.
KNIGHT, V.M.; YOUNG, C.E.F. Custo da poluição gerada pelos ônibus urbanos na RMSP. In: ANPEC, 34, 2006, Salvador. Disponível em:

<http://www.anpec.org.br/encontro2006/artigos/A06A069.pdf>. Acesso em: 15 maio 2007.

MACHADO, H.V. A identidade e o contexto organizacional: perspectivas de análise. Revista de Administração Contemporânea, Curitiba, v.7, p.51-73, 2003. Edição Especial.

MALHOTRA, N.K. Pesquisa em marketing: uma orientação aplicada. Porto Alegre: Bookman, 2001. 719p. Tradução Nivaldo Montingelli Junior.

MEIRA, F.B. Responsabilidade social e ideologia: notas sobre a gênese de um conceito. In: ENANPAD, 30, 2006, Salvador. Anais... Salvador. 1 CD-ROM.

MELO NETO, F.P.; FROES, C. Gestão da responsabilidade social corporativa: o caso brasileiro. Rio de Janeiro: Qualitymark, 2001. 189p.

Responsabilidade social e cidadania empresarial: a administração do terceiro setor. Rio de Janeiro: Qualitymark, 1999. 190p.

PAIXÃO, M. Relações de trabalho na agroindústria sucroalcooleira do Brasil: exclusão ou cidadania? In: FERRAZ, J.M.G.; PRADA, L.S.; PAIXÃO, M. Certificação sociambiental do setor sucroalcooleiro. São Paulo: Embrapa Meio Ambiente, 2000. p.111-146.

PANWAR, R. et al. Corporate responsibility: balancing economic, environmental, and social issues in the forest products industry. Forest Products Journal, v.56, n.2, p.4-12, feb. 2006.

PASSADOR, C.S.; CANOPF, L.; PASSADOR, J.L. Apontamentos sobre a responsabilidade social no ENANPAD: a construção de um conceito? In: ENANPAD, 29, 2005, Brasília. Anais... Brasília. 1 CD-ROM. 
ROMANACH, L.M.; CARON, D. Impactos da mecanização da colheita de cana sobre o emprego, a gestão empresarial e o meio ambiente: um estudo de caso. In: SOBER, 27, 1999, Foz do Iguaçu. Disponível em: <http://gipaf.cnptia.embrapa.br/ itens/publ/sober/trab121.pdf>. Acesso em: 21 fevereiro 2006.

ROSSETTO, R. A cultura da cana, da degradação à conservação. Visão Agrícola, Piracicaba, v.1, n.1, p.80-85, jan./jun.2004.

RUI, J.D. A responsabilidade social no setor sucroalcooleiro. JornalCana, Ribeirão Preto, dez.2004. Disponível em: <www. jornalcana.com.br>. Acesso em: 22 fev. 2006.

SENGE, P. M.; CARSTEDT, G. Rumo à próxima revolução industrial. HSM Management, São Paulo, a.5, n.27, p.120-128, jul./ago. 2001

SERVA, M. A racionalidade substantiva demonstrada na prática administrativa. Revista de Administração de Empresas, São Paulo, p.18-30, v.37, n.2, abr./jun.1997.
SHARMA A. K.; TALWAR, B. Corporate social responsibility: modern vis-à-vis Vedic approach. Measuring Business Excellence, v.9, n.1, p.35-45, 2005.

SHIKIDA, P.F.A.; NEVES, M.F.; REZENDE, R.A. Notas sobre dinâmica tecnológica e agroindústria canavieira no Brasil. In: MORAES, M.A.F.D.; SHIKIDA, P.F.A. (Coords.). Agroindústria canavieira no Brasil: evolução, desenvolvimento e desafios. São Paulo: Atlas, 2002. p.125-127.

TETTI, L.M.R. Protocolo de Kyoto: Oportunidades para o Brasil com base em seu setor sucroalcooleiro: um pouco da história da questão "mudanças climáticas e efeito estufa". In: MORAES, M.A.F.D.; SHIKIDA, P.F.A. (Coords.). Agroindústria canavieira no Brasil: evolução, desenvolvimento e desafios. São Paulo: Atlas, 2002. p.202-206.

UNIÃO DA INDÚSTRIA DE CANA-DE-AÇÚCAR. Açúcar e álcool: responsabilidade social numa história de desenvolvimento sustentável. São Paulo, 2004. 16p.

\section{Sobre os autores}

Ivelise Rasera Bragato

\section{Elisabete Stradiotto Siqueira}

Graziela Oste Graziano

\section{Eduardo Eugênio Spers}

Mestrado Profissional em Administração, Universidade Metodista de Piracicaba - UNIMEP,

Rodovia do Açúcar - Km 156, CEP 13400-911, Piracicaba, SP, Brasil,

e-mails: irbragat@esalq.usp.br; betebop@uol.com.br; grabela@terra.com.br, eespers@unimep.br 